551.510 .42

\title{
Atmospheric Pollution in Tokyo District
}

\author{
- On Atmospheric Pollution (IV)-
}

by

\author{
M. Moriguchi, K. Itoo, K. Kamiyama, N. Yano, H. Naruse \\ Meteorological Research Institute \\ and $\mathrm{H}$. Yamaguchi \\ Tokyo Medical and Dental University. \\ (Received October 17, 1956)
}

\begin{abstract}
In order to find a clue to the present situation of the atmospheric pollution in Tokyo, two points near the atmospheric pollution sources in Tokyo city (Kanda* and Arakawa**) and one*** in Kawasaki city which seemed to exercise much effect on the pollution in Tokyo city were selected, and the concentration of $\mathrm{SO}_{2}, \mathrm{CO}_{2}$ and dust in the open air were observed 5 times per day during a week, from 15th to 21st February, 1956. And also, $\mathrm{H}-\mathrm{CHO}$ and $\mathrm{NH}_{3}$ in the air were observed at the same time respectively in Kanda and Arakawa. Depending on the results obtained, the characteristics of the atmospheric pollution in its source area were investigated. Especially, the $\mathrm{SO}_{2}$ concentration was compared with the concentration and its variation which were observed at 7 localities in Kanda and others last year.
\end{abstract}

\section{Introduction}

As a clue to the atmospheric pollution in Tokyo city, which has been a matter of concern in recent years, the authors conducted their observation on the $\mathrm{SO}_{2}$ concentration in the air at 7 localities in Tokyo city in February, 1955 , and already reported it in its relations to the meteorological factors [1], [2], [3]. This time, 3 points were selected on the basis of the results obtained last year (Fig. 1): Arakawa, the atmosheric pollution source area in the northeastern part of Tokyo city; Kawasaki city in the southern source area; Kanda, a common observation point with last year, for the purpose of comparing with the results of this year. Polluted air

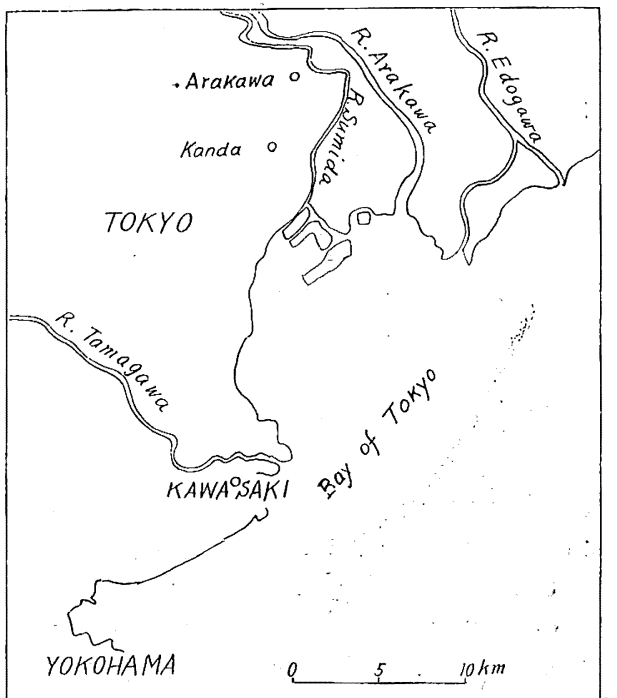

Fig. 1. Lacality of observation.

** The Arakawa Post Office.

* The Tokyo Medical and Dental University. *** The Sakuramoto Elementary School. 
was sucked in 5 times per day, at $9 \mathrm{~h}, 12 \mathrm{~h}, 15 \mathrm{~h}, 18 \mathrm{~h}$ and $21 \mathrm{~h}$. Observed contaminants were $\mathrm{SO}_{2}, \mathrm{CO}_{2}$ and dust in the air, but especially minute observation was conducted on the $\mathrm{CO}_{2}$ concentration, because the concentration of atmospheric $\mathrm{CO}_{2}$ in great cities has recently been taken up as an important problem among the hygienists in Japan. And atmospheric H-CHO was observed in Kanda in order to see the effect by the waste gas from vehicles in consideration of the increasing traffic. In Arakawa it was necessary to detect $\mathrm{NH}_{3}$ in the air from the view point of its areal characteristics.

\section{General procedures}

1) Location of observation points

The reason why the 3 points were selected was given above. The purpose of that work was to observe meteorologically the conditions of the atmospheric pollution in its source area and to investigate its characteristics, and to find a clue to further investigation. Consequently, places adjacent to the chimneys were eliminated in selecting observation points because the operative condition of the chimneys would have direct effect on the author's observation. The values thus obtained may express less than the representative one, in view of the position of the observation point in each area. Every observation point had an inlet of the sample air at the height of 4 to 8 meters.

2) Selection of observation period

The authors selected the winter season when the atmosphere is comparatively stable and high concentration is produced in Tokyo. However, the observation

Table. 1. The wind directions, wind velocities $(\mathrm{m} / \mathrm{sec})$ and weather conditions during the observation period.

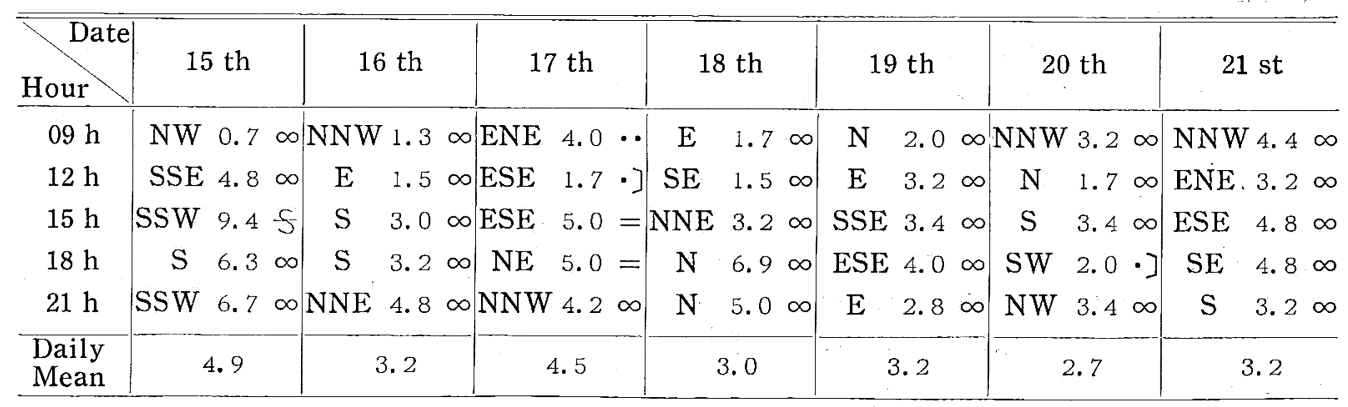

condition of this year was not so favorable as that of last year because the Siberian anticyclone was comparatively poor throughout that period. The wind direction, the wind velocity and the weather observed at the Japan Meteorological Agency during that period are shown in Table 1.
Table. 2. Chemical change applied to the measurement and the volume of air used in each measurement.

\begin{tabular}{llr}
\hline $\mathrm{SO}_{2}:$ & $\mathrm{SO}_{2}+\mathrm{H}_{2} \mathrm{O}_{2}=\mathrm{H}_{2} \mathrm{SO}_{4}$ & $60 l$ \\
$\mathrm{CO}_{2}:$ & $\mathrm{CO}_{2}+\mathrm{Ba}(\mathrm{OH})_{2}=\mathrm{BaCO}_{3}+\mathrm{H}_{2} \mathrm{O}$ & $1 l$ \\
$\mathrm{HCHO}:$ & $\mathrm{HCHO}+\mathrm{NaHSO}_{3} \rightarrow \mathrm{HCH}<\mathrm{SO}_{3} \mathrm{Na}$ & $120 l$ \\
$\mathrm{NH}_{3}:$ & $2 \mathrm{NH}_{3}+\mathrm{H}_{2} \mathrm{SO}_{4}=\left(\mathrm{NH}_{4}\right)_{2} \mathrm{SO}_{4}$ & $60 l$ \\
\hline
\end{tabular}




\section{3) Method of measurement}

Chemical change applied to the measurement and the volume of the air used in each measurement are given in Table 2. All other methods of measurement but $\mathrm{H}$-CHO have been authorized in Japan. Filter paper was used for measuring dust, and $60 l$ of the air once was sucked in through the filter paper (a sheet per day) 5 times per day.

\section{Results obtained}

Of the results of the observation, the concentrations of $\mathrm{SO}_{2}, \mathrm{CO}_{2}$ and $\mathrm{H}-\mathrm{CHO}$ observed at each locality are shown in Table 3.

Table. 3. The concentrations of $\mathrm{SO}_{2}, \mathrm{CO}_{2}$ and $\mathrm{H}-\mathrm{CHO}$ observed at each locality.

\begin{tabular}{|c|c|c|c|c|c|c|c|c|}
\hline \multicolumn{5}{|c|}{$\begin{array}{c}\mathrm{SO}_{2} \text { concentration (p. p. m.) } \\
\text { at each locality }\end{array}$} & \multicolumn{3}{|c|}{$\begin{array}{c}\mathrm{CO}_{2} \text { concentration }(\%) \\
\text { in each locality }\end{array}$} & $\begin{array}{c}\mathrm{H}-\mathrm{CHO} \\
\text { concentration } \\
\text { (p.p.m.) at }\end{array}$ \\
\hline Date & Hour & Kanda & Kawasaki & Arakawa & Kanda & Kawasaki & Arakawa & Kanda \\
\hline 15 & $\begin{array}{r}9 \\
12 \\
15 \\
18 \\
21\end{array}$ & $\begin{array}{l}0.027 \\
0.093 \\
0.068 \\
0.063 \\
0.052\end{array}$ & $\begin{array}{l}0 \\
0.116 \\
0.048 \\
0.061 \\
0.045\end{array}$ & $\begin{array}{l}0.028 \\
0.011 \\
0.024 \\
0.015 \\
0.003\end{array}$ & $\begin{array}{l}0.031 \\
0.030 \\
0.028 \\
0.032 \\
0.028\end{array}$ & $\begin{array}{l}0.089 \\
0.042 \\
0.035 \\
0.074 \\
0.046\end{array}$ & $\begin{array}{l}0.049 \\
0.035 \\
0.042 \\
0.046 \\
0.038\end{array}$ & $\begin{array}{l}0.013 \\
0.010 \\
0.014 \\
0.017 \\
0.013\end{array}$ \\
\hline 16 & $\begin{array}{r}9 \\
12 \\
15 \\
18 \\
21\end{array}$ & $\begin{array}{l}0.053 \\
0.050 \\
0.104 \\
0.112 \\
0.047\end{array}$ & $\begin{array}{l}0.036 \\
0.043 \\
0.057 \\
0.144 \\
0.048\end{array}$ & $\begin{array}{l}0 \\
0.011 \\
0.006 \\
0.005 \\
0.014\end{array}$ & $\begin{array}{l}0.035 \\
0.053 \\
0.044 \\
0.045 \\
0.038\end{array}$ & $\begin{array}{l}0.030 \\
0.030 \\
0.035 \\
0.055 \\
0.053 .\end{array}$ & $\begin{array}{l}0.045 \\
0.053 \\
0.047 \\
0.042 \\
0.042\end{array}$ & $\begin{array}{l}0.013 \\
0.033 \\
0.023 \\
0.025 \\
0.025\end{array}$ \\
\hline 17 & $\begin{array}{r}9 \\
12 \\
15 \\
18 \\
21\end{array}$ & $\begin{array}{l}0.013 \\
0.016 \\
0.036 \\
0.021 \\
0.011\end{array}$ & $\begin{array}{l}0.044 \\
0.060 \\
0.010 \\
0.001 \\
0.003\end{array}$ & $\begin{array}{r}0 \\
0.008 \\
0.008 \\
-0.033 \\
-0.014\end{array}$ & $\begin{array}{l}0.053 \\
0.043 \\
0.048 \\
0.048 \\
0.042\end{array}$ & $\begin{array}{l}0.028 \\
0.104 \\
0.055 \\
0.045 \\
0.050\end{array}$ & $\begin{array}{l}0.040 \\
0.040 \\
0.042 \\
0.051 \\
0.046\end{array}$ & $\begin{array}{l}0.019 \\
0.030 \\
0.032 \\
0.039 \\
0.019\end{array}$ \\
\hline 18 & $\begin{array}{r}9 \\
12 \\
15 \\
18 \\
21\end{array}$ & $\begin{array}{l}0.056 \\
0.041 \\
0.151 \\
0.005 \\
0.028\end{array}$ & $\begin{array}{l}0.014 \\
0.017 \\
0.010 \\
0.031 \\
0.020\end{array}$ & $\begin{array}{l}0.021 \\
0.016 \\
0.006 \\
0.007 \\
0.002\end{array}$ & $\begin{array}{l}0.041 \\
0.039 \\
0.053 \\
0.050 \\
0.054\end{array}$ & $\begin{array}{l}0.051 \\
0.065 \\
0.051 \\
0.056 \\
0.046\end{array}$ & $\begin{array}{l}0.050 \\
0.047 \\
0.050 \\
0.041 \\
0.052\end{array}$ & $\begin{array}{l}0.021 \\
0.039 \\
0.028 \\
0.024 \\
0.013\end{array}$ \\
\hline 19 & $\begin{array}{r}9 \\
12 \\
15 \\
18 \\
21\end{array}$ & $\begin{array}{l}0.005 \\
0 \\
0.015 \\
0.014 \\
0.016\end{array}$ & $\begin{array}{l}0.008 \\
0.001 \\
0.002 \\
0.036 \\
0.005\end{array}$ & $\begin{array}{r}0.028 \\
0.010 \\
-0.009 \\
0.011 \\
0.002\end{array}$ & $\begin{array}{l}0.036 \\
0.036 \\
0.031 \\
0.034 \\
0.048\end{array}$ & $\begin{array}{l}0.050 \\
0.051 \\
0.047 \\
0.056 \\
0.053\end{array}$ & $\begin{array}{l}0.053 \\
0.053 \\
0.043 \\
0.041 \\
0.045\end{array}$ & $\begin{array}{l}0.031 \\
0.031 \\
0.026 \\
0.025 \\
0.020\end{array}$ \\
\hline 20 & $\begin{array}{r}9 \\
12 \\
15 \\
18 \\
21\end{array}$ & $\begin{array}{l}0.056 \\
0.031 \\
0.099 \\
0.050 \\
0.029\end{array}$ & $\begin{array}{l}0.078 \\
0.079 \\
0.093 \\
0.027 \\
0.087\end{array}$ & $\begin{array}{r}-0.005 \\
0.009 \\
0.037 \\
0.026 \\
0.001\end{array}$ & $\begin{array}{l}0.045 \\
0.028 \\
0.037 \\
0.035 \\
0.037\end{array}$ & $\begin{array}{l}0.087 \\
0.080 \\
0.069 \\
0.048 \\
0.083\end{array}$ & $\begin{array}{l}0.035 \\
0.043 \\
0.042 \\
0.049 \\
0.050\end{array}$ & $\begin{array}{l}0.011 \\
0.013 \\
0.011 \\
0.015 \\
0.008\end{array}$ \\
\hline 21 & $\begin{array}{r}9 \\
12 \\
15 \\
18 \\
21\end{array}$ & $\begin{array}{l}0.039 \\
0.021 \\
0.006 \\
0.016 \\
0.050\end{array}$ & $\begin{array}{l}0.052 \\
0.034 \\
0.040 \\
0.104 \\
0.032\end{array}$ & $\begin{array}{r}-0.005 \\
0.015 \\
-0.005 \\
0.004 \\
0.008\end{array}$ & $\begin{array}{l}0.040 \\
0.031 \\
0.056 \\
0.040 \\
0.036\end{array}$ & $\begin{array}{l}0.086 \\
0.075 \\
0.090 \\
0.069 \\
0.062\end{array}$ & $\begin{array}{l}0.042 \\
0.038 \\
0.032 \\
0.041 \\
0.040\end{array}$ & $\begin{array}{l}0.008 \\
0.015 \\
0.015 \\
0.006 \\
0.005\end{array}$ \\
\hline
\end{tabular}


1) Atmospheric $\mathrm{SO}_{2}$

In Fig. 2 are shown the daily mean concentration of atmospheric $\mathrm{SO}_{2}$ and its total mean concentration (indicated by the shading poles) at each observation point. It is a phenomenon seen last year at the observation points adjacent to the

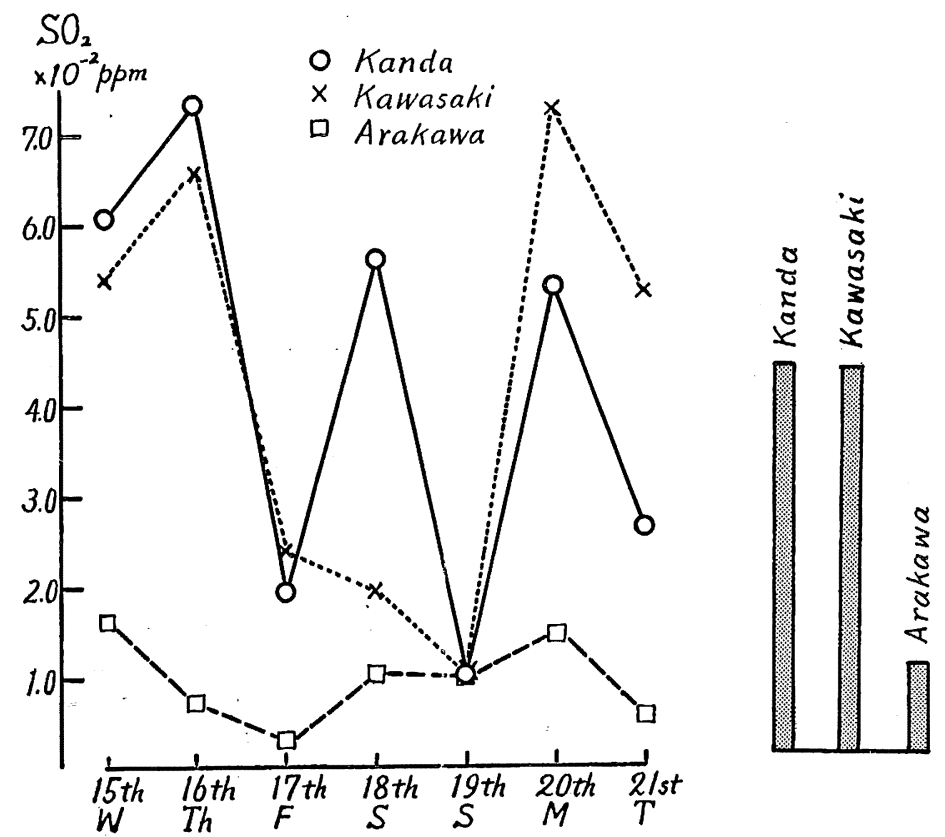

Fig. 2. Daily mean concentration of $\mathrm{SO}_{2}$ and its total mean concentration at each locality.

pollution source that the daily mean concentration varies sharply from day to day, and it seems that the variation in Kanda and in Kawasaki correspond considerably well to each other except on 18 th. The data on hand are too scarce to explain the relation between those variations and the meterological factors, but the operative condition of the chimneys and the relative position of the observation points to the chimneys may be much influential. Here, the noteworthy fact is that the concentration on 19 th. Sunday, shows the same minimum value as obtained at the observation points last year. In the total mean concentration, Kanda is equal to Kawasaki showing the value of $0.04 \mathrm{ppm}$, which is equivalent to total mean concentration obtained in Kanda last year. The total mean concentration in Arakawa is lower than expected, showing $0.01 \mathrm{ppm}$, which will be explained later.

Fig. 3 shows the mean concentrations in each of the observation points, which are classified into two categories $\mathrm{S}$ and $\mathrm{N}$ by wind directions, where $\mathrm{S}$ represents the wind direction of $\mathrm{E} \sim \mathrm{S}$ and $\mathrm{N}$ that of $\mathrm{W} \sim \mathrm{N}$. Excepting the case of the wind force $0 \sim 1$, in Kawasaki, the concentration belonging to the south category is higher. It would be concluded in view of the results so far obtained at the observation points this year that comparatively strong wind in the south component acts as pollution conveyor rather than as diffusion factor. 

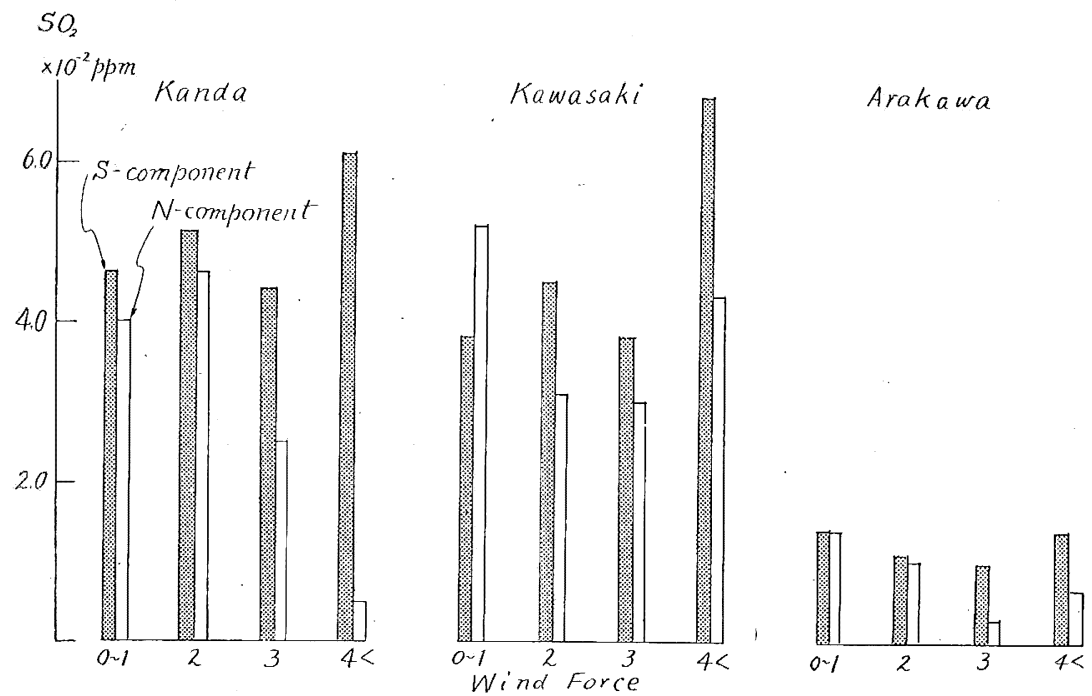

Fig. 3. The mean concentration of $\mathrm{SO}_{2}$ versus wind forces at each locality.

Fig. 4 shows the hourly mean concentration, which is comparatively higher between $12 \mathrm{~h}$ and $18 \mathrm{~h}$, with the interdependence of the meteorological condition under which the south component wind easily blows in the daytime, and the operative condition of the chimneys.
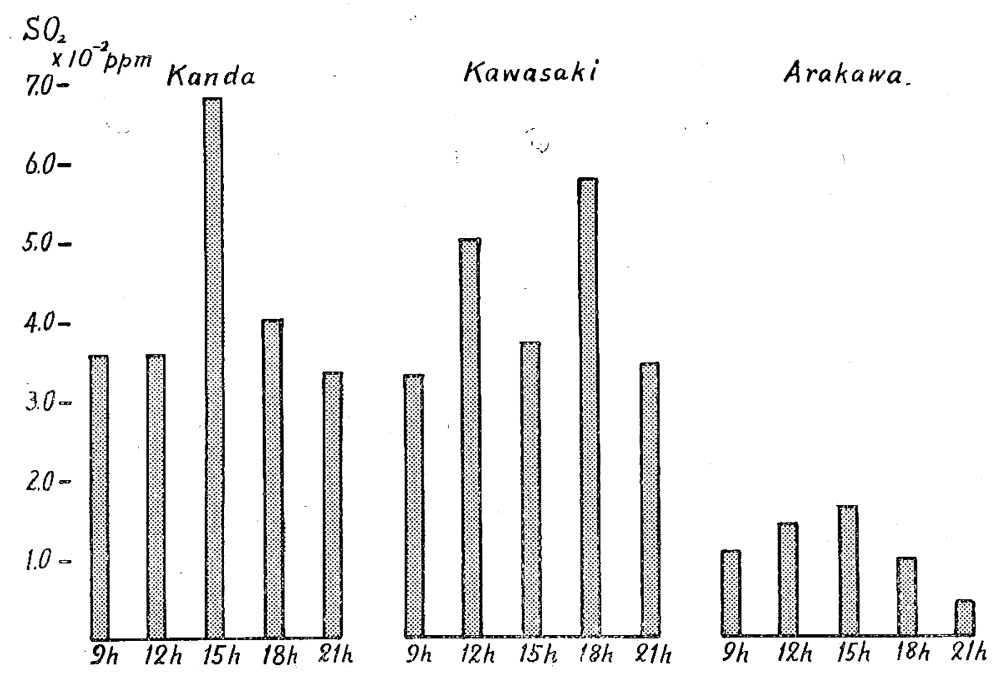

Fig. 4. Hourly mean concentration of $\mathrm{SO}_{2}$ at each locality.

2) Atmospheric $\mathrm{CO}_{2}$

Fig. 5 shows the daily mean concentration of atmospheric $\mathrm{CO}_{2}$ at each observation point. The shading poles on the right side indicate the total mean concentration, the values of which are $0.040 \%, 0.058 \%$ and $0.044 \%$ respectively in Kanda, Kawasaki and Arakawa. Those in Kanda and Arakawa are almost equal 


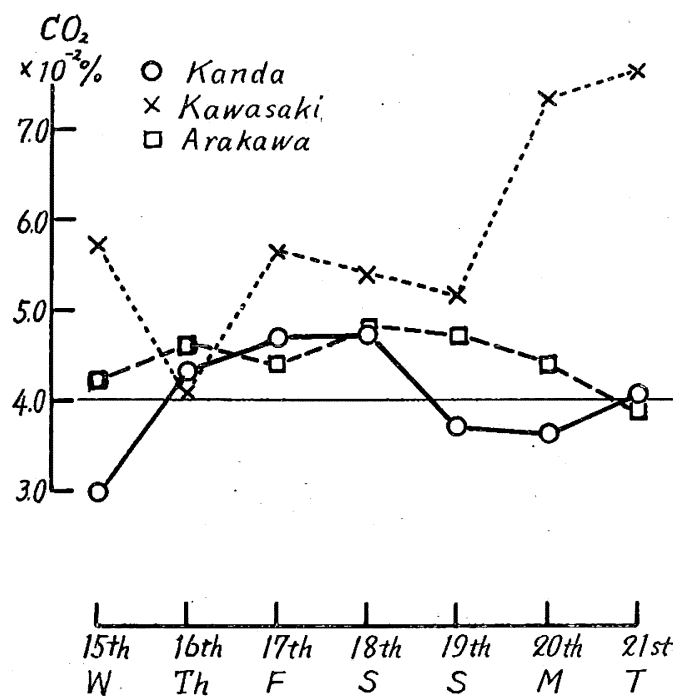

Fig. 5. Daily mean concentration of $\mathrm{CO}_{2}$ and its total mean concentration.

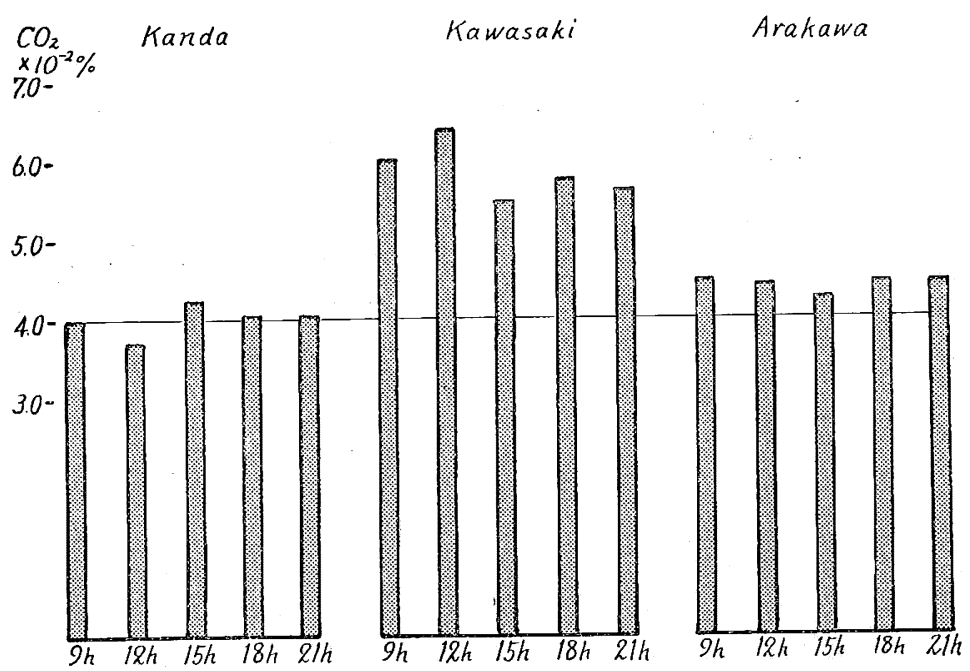

Fig. 6. Hourly mean concentration of $\mathrm{CO}_{2}$ at each locality.

to the values which were already authorized in Japan, but in Kawasaki the daily variation is wider, and the total mean concentration is conspicuously higher. That is to say, both factors of observation points and of days are significant according to the result of analysis of variance.

Fig. 6 shows the hourly mean concentration. The variations of these individual values are far small as compared with that of $\mathrm{SO}_{2}$.

3) Atmospheric Dust

A paper disk with a free filtration area of $3.8 \mathrm{sq} \mathrm{cm}$ is provided for the collection of atmospheric dust particles. The collection efficiency in ordinary dust of 
this filter paper is expected to be fairly well [4]. In this paper the relation between the qualitative estimation of the amount of the dust collected by the filter paper and the other atmospheric pollution will be described.

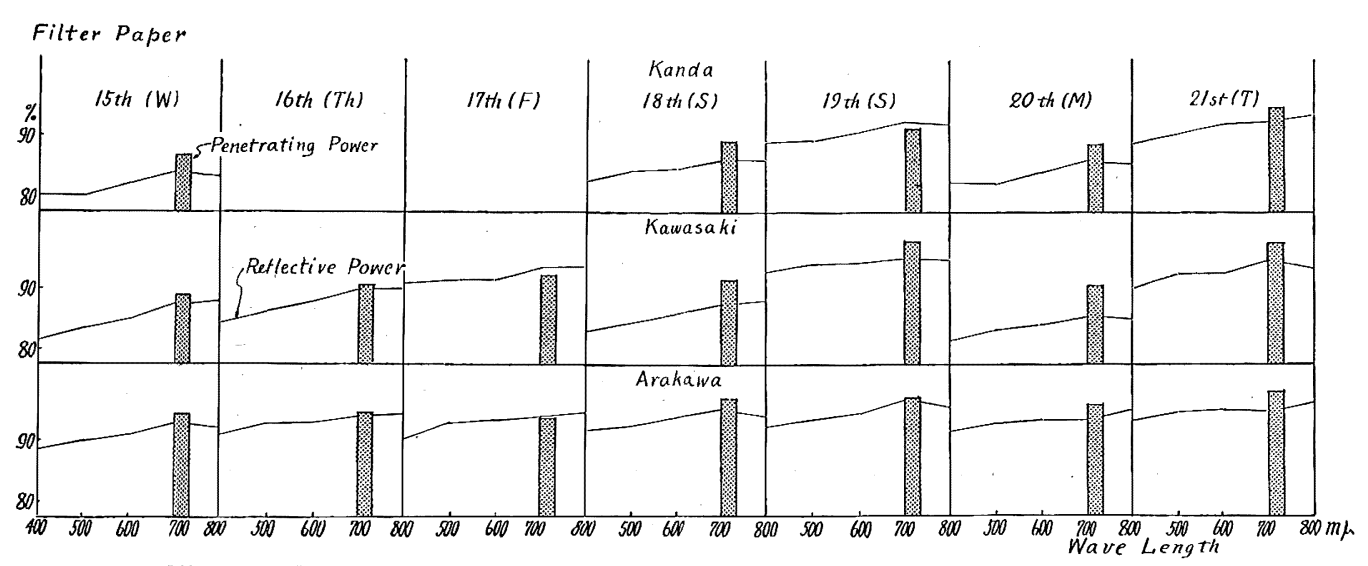

Fig. 7. The comparison of the amount of reflected and transmitted light for the dust spot on the filter paper.
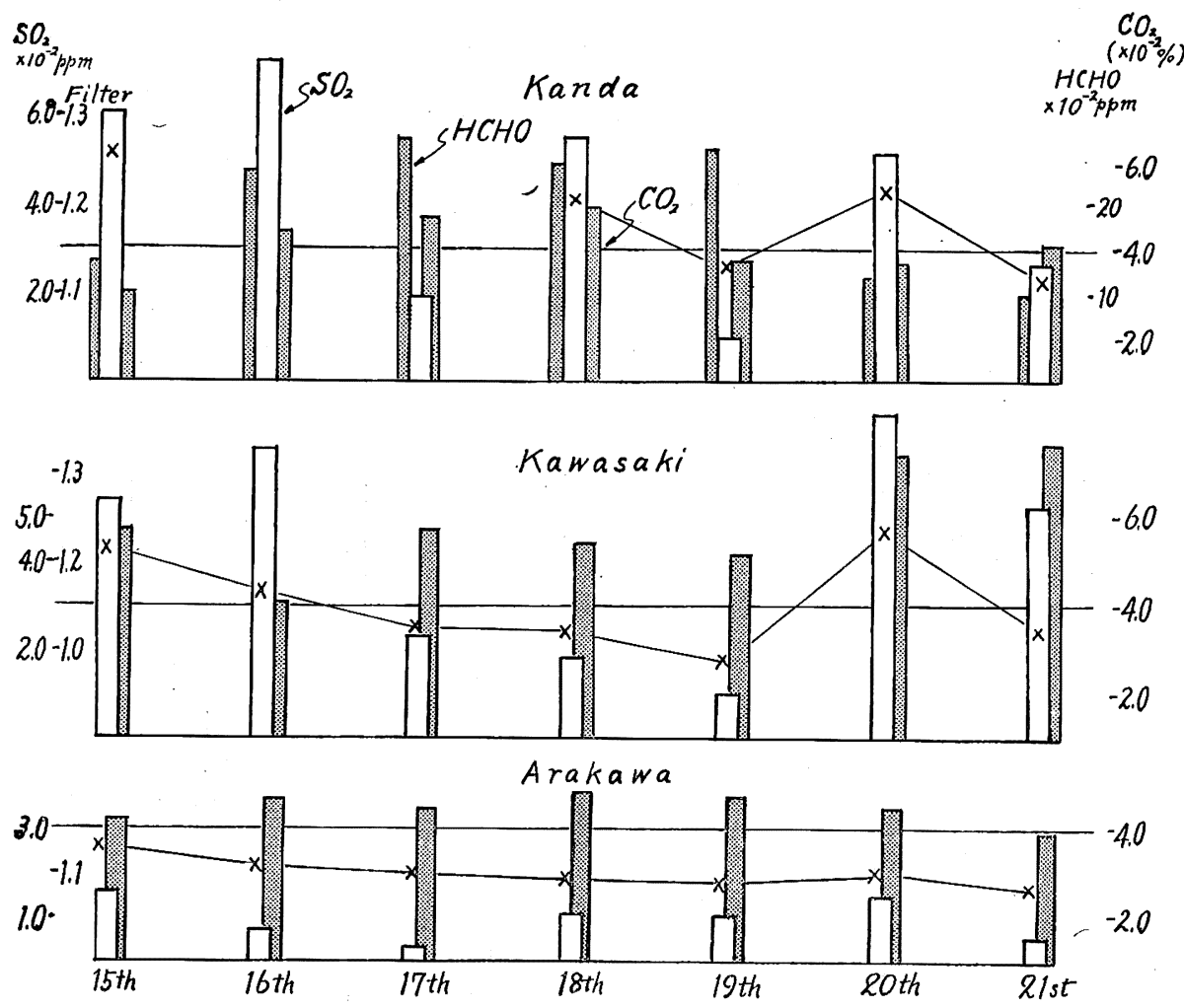

Fig. 8. The comparison of the dust pollution with the other asmospheric pollution. 
Fig. 7 shows the comparison of the amount of reflected and transmitted light for the dust spot on the filter paper. As seen in Fig. 7 the two follow comparatively well, and the comparison of the dust pollution with the other atmospheric pollution, by the aid of the reciprocal of the transmittance, is given in Fig. 8. In Arakawa the $\mathrm{SO}_{2}$ concentration is too low, while the dust pollution follows comparatively well the variation of the $\mathrm{SO}_{2}$ concentration in the other two points. Such a phenomenon as seen in Arakawa will be explained in the following.

\section{4) Atmospheric $\mathrm{NH}_{3}$ in Arakawa}

As the measurement of the atmospheric $\mathrm{SO}_{2}$ depends on the measurement of $\mathrm{pH}$ changes, sometimes minus values of its concentration were obtained in Arakawa during the observation period as shown in Table 3. In setting up the observation points, the neighbourhood of such a pollution source as has direct effect on the observation was avoided as far as possible, but Arakawa is, as it were, the slum of Tokyo, and manual industries, garbage, and sewage might have more influence on the $\mathrm{SO}_{2}$ concentration there. Fig. 9 shows its example, according to which alkaline gas is more influential in the early morning and at night when the lower atmosphere is stable, and the factories are mostly at rest $-1.6 \gamma \mathrm{NH}_{3}$ are detected in $60 l$ of the air sucked in during $2 \mathrm{~h} 30 \mathrm{~m} \sim 3 \mathrm{~h} 30 \mathrm{~m}, 22 \mathrm{nd}$, which is equivalent to $0.018 \mathrm{ppm}$ of the $\mathrm{SO}_{2}$ concentration. Such being the case, it is wrong to estimate atmospheric pollution in terms of $\mathrm{SO}_{2}$ concentration by the measurement of $\mathrm{pH}$, and yet the questions remain on the measurement of the atmospheric pollution of such peculiar kind and its estimation.

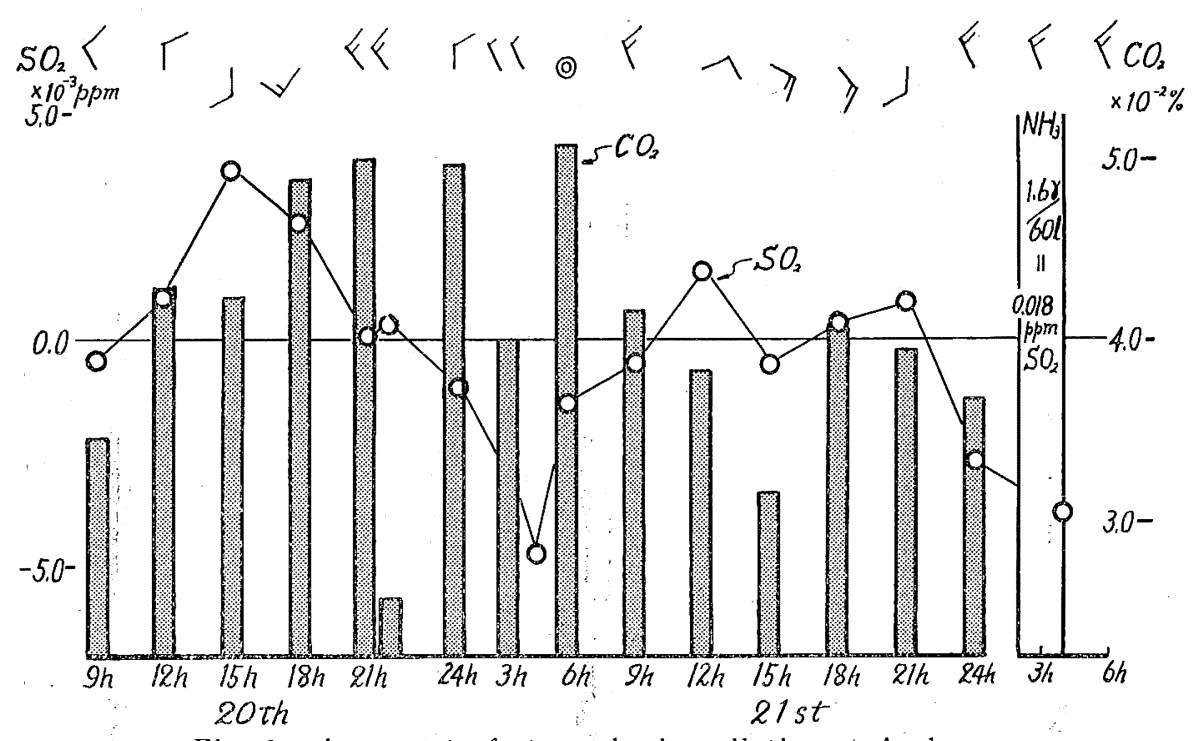

Fig. 9. An aspect of atmospheric pollution at Arakawa.

5) Atmospheric H-CHO.

Fig. 10 shows the daily-, hourly-, and the total mean concentration of $\mathrm{H}$-CHO measured in Kanda. The "observation point is away from busy streets, but the total mean concentration is $0.02 \mathrm{ppm}$ and according to the result of the 

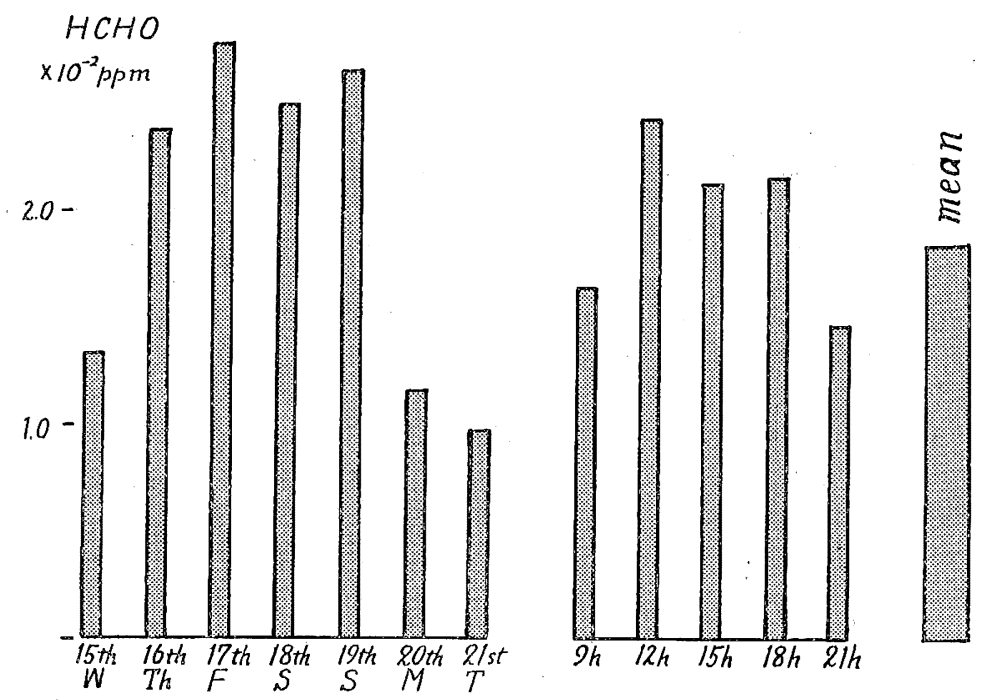

Fig. 10. Daily, hourly and total mean concentration of H-CHO measured in Kanda.

analysis of variance the factors of days and hours are significant at $1 \%$ and $5 \%$ levels respectively.

\section{Some consideration}

Concerning the results obtained from that observation :

1) As for the $\mathrm{SO}_{2}$ concentration, only lower concentration is obtained in Kawasaki and Arakawa than had been expected from them as pollution source areas. The values are not representative of those areas, and rather they seem to indicate the minimum in view of the position of the observation points. In other words, the atmospheric pollution is not uniformly diffused in those source areas. Locally or hourly the pollution being remarkably different in concentration, it is quite impossible to estimate the pollution condition at one observation point in such short-period observation. The problem should be taken up on the atmospheric pollution of a peculiar kind in Arakawa and others.

2) Regarding the $\mathrm{CO}_{2}$ concentration, it is known that there is a certain area showing regularly a considerably high concentration (the highest reaches $0.09 \%$ ) such as in Kawasaki. Hence, it is a procedure of doubtful propriety, when locally special circumstances do prevail, to estimate indiscriminately the $\mathrm{CO}_{2}$ concentration in the open air as $0.04 \%$, and to utilize it mechanically as a standard for measuring the ration of ventilation in the room.

Acknowledgements-The authors wish to express their sincere thanks to Dr. Kita, Professor of the Tokyo Medical and Detal University, for his encouragement and useful suggestions. 


\section{References}

[1] Itoo, K., Moriguchi, M. and Naruse, H., 1955: Atmospheric $\mathrm{SO}_{2}$ Concentration Observed in Tokyo and Its Relation to Meteorological Elements. Pap. Met. Geophys., 4, p. 19.

[2] Moriguchi, M., 1955: Atmospheric $\mathrm{SO}_{2}$ in Tokyo District. Pap. Met. Geophys. 5, p. 144.

[3] Мовіябсні, M. and Iтоо, K. 1956: Electronmicroscope Study of Atmospheric Pollution. Pap. Met. Geophys. 6, p. 255.

[4] Drinker, P. and HATCH, T., 1954: Industrial Dust. McGrawhill. p. 127. 